\title{
Mobile Marketing in Japan
}

\author{
Noah H. N. Lynn \\ Bentley University \\ 175 Forest St., Waltham, MA 02452, U.S.A.
}

Tel: 1-781-454-6652Ｅ-mail: lynn.noah@gmail.com

Paul D. Berger (Corresponding author)

Bentley University

175 Forest St., Waltham, MA 02452, U.S.A.

Tel: 1-617-974-5888Ｅ-mail: pberger@bentley.edu

Received: August 17, 2014 Accepted: September 9, 2014 Published: September 25, 2014

doi:10.5296/ijssr.v2i2.6154 URL: http://dx.doi.org/10.5296/ijssr.v2i2.6154

\begin{abstract}
In this paper we describe the state of mobile marketing in Japan. We consider the various aspects of mobile marketing in Japan and what has led to the overwhelming adoption by Japanese youth, and to a degree Japanese society as a whole, of social media and associated activities. This growth of mobile marketing has dramatic, positive implications for marketing, in general, as well as for the sale of selected product classes. We also consider markers for suggesting what the future of mobile marketing will be in Japan and around the world. Finally, a key implication for optimal marketing strategy is discussed.
\end{abstract}

Keywords: Mobile Marketing, Marketing in Japan, Social Media, Mobile Advertising, Customer Lifetime Value (CLV)

\section{Introduction}

Mobile marketing shines in Japan. Mobile technology first arrived there in 1999, long before many other countries, so that companies have now had 25 years to test and recalibrate their approaches. At the same time, sociological surveys have revealed the complex factors behind why Japanese consumers like, dislike, trust or distrust mobile outreach tactics. All of the building blocks are now in place for Japan's mobile marketing to burst into a golden age. 
From the potent culture of word-of-mouth buzz, word-of-Web, and online reviews, to mobile apps that offer exciting customer experiences, Japanese consumers have put themselves at the center of marketing campaigns. High-speed internet connections and high tech smart phones are ubiquitous in Japan, creating a super highway on which innovative marketers deliver their messages. And, studies have shown that campaigns can be successful by following a few simple tenets: be personal, purposeful and private, and entertain without irritating the consumer. As time goes on, Japan seems poised to set the standard in mobile marketing for all the rest of the world to follow.

\section{The Importance of Being OThLY}

A 24-year old Japanese office worker posts a video online. She goes only by the name Yayoi, and in the video discusses her love of stars. She points to her personal collections of star candles, star hair clips, star trinkets, etc., and explains that "Stars make me feel happy, because I feel as though their radiance is somehow transferred to me (Sanchanta, 2004)." Up to this point, Yayoi sounds no different than any social media proficient millennial ${ }^{1}$ from around the world. However, before signing off, she utters the words that make Japanese mobile-marketing agencies drool, "When it comes to stars, money is no object." Yayoi is a member of a growing sub-culture of young Japanese product fanatics; their social circles are defined by their knowledge of particular products, they have prolific social media footprints, and they have money to spend on sharpening their expertise. David McCaughan, the Regional Director (APAC) of McCann Truth Central in Tokyo, has dubbed these product fanatics the neo-otaku (McCaughan, 2010).

The term otaku in Japan is traditionally used to mean a young male who is a super-fan (or pejoratively, a super-nerd) of manga graphic novels. There are as many subcultures of otaku as there are genres of manga, and Japanese society eyes these incredibly dedicated anime ${ }^{2}$ fans with guarded suspicion of how their values mix with the culture at large. According to Mr. McCaughan, the appearance of these neo-otaku on the consumer scene raised similar suspicions of their socialization, although they are more accepted now. "Fourteen years ago when I started giving presentations about otaku, it was written up at the time in the Japanese press as possibly the greatest threat to society ever known." (Of course, the same fear about the "greatest threat to society ever known" arose in the United States and Great Britain [and, eventually most of the developed world - including Japan] in the 1960's with the arrival of the Beatles, The Rolling Stones, counter culture, and the accompanying recreational drug culture.) However, continues Mr. McCaughan, "These were [simply] weird, obsessed kids who spent hours each day researching one subject on their computers. Well, now we call that normal (McCaughan, 2010)."

\footnotetext{
1 "Millennials" are the demographic group following Generation X. There are no precise birth dates when the generation starts and ends. Researchers and commentators use birth years ranging from the early 1980s to the early 2000s. For example, the McCrindle Research Center uses 1980-1994, while the Australian Bureau of Statistics uses 1982-2000.

2 A Japanese style of animated cartoon, often with violent or sexually explicit content.
} 


\section{Macrothink}

They are indeed the new normal. Their passports into new social groups are their online reviews. Their street "cred" (credibility) is built on Facebook preferences and re-tweeted posts. The more they impress their peers with the knowledge of certain products, the more respect they gain. These traits are, in fact, common among young people around the world. McCann Erickson's study "The Truth About Social," based on surveys of global youth including in Japan, reports that "Globally, over $90 \%$ of 16-30 year olds agree with the statement 'if a company or brand impresses me in some way, I will make a point of telling my friends about it.' Meanwhile, data from our Truth About Beauty study showed us that female consumers rated online product reviews as a) the most truthful source available to them and b) the source most likely to prompt purchase (The Truth About Social, 2011)."

One might speculate that much of the above is an online, social-media continuation of society, in general, becoming more materialistic. Fournier and Richins (1991), in a study of popular notions concerning materialism, found that people of all types describe materialistic individuals in a similar manner, noting that "they have to have the material things ... in order for them to be happy" and "their happiness is dependent on whether they get what they want." According to theoretical and popular conceptions, materialistic consumers expect the acquisition of possessions to improve their well-being. They value their possessions, although the value they place is not consistent for all products or product categories, and there is, of course, variance among consumers. Materialism develops when individuals are exposed to social models that encourage materialistic values (Kasser et al., 2004). Some possessions are conspicuously consumed. Veblen (1899) coined his now famous phrase "conspicuous consumption," referring to spending that satisfies no need other than to build prestige, a cultural signifier intended to intimidate and impress. Possessions often reveal characteristics of their owners, indicating the kind of people they are or perceive themselves to be. Some might feel that material possessions have a worth greater than their market value. The comfort associated with being surrounded by items helps some people feel optimistic about the future and good about the present. To some, connections with certain products (e.g., smart phones, computers, and several others) are very important in feeling a sense of belonging with a particular group or category of individuals.

Perhaps, much of the above discussion of materialism is not so conceptually different from the efforts made by Otaku to impress peers through product knowledge. Much of the discussion can be rewritten with mobile marketing and social media replacing other aspects of materialism. One might argue that it is simply a change in the definition of materialism and possession.

What makes Japanese mobile-marketing agencies so excited is that these neo-otaku are not just children, but they are increasingly single workers in their twenties. These young adults do not have lifetime employment nor the security to start a family ("benefits" which, up to about 25 years ago, were the bedrock of post-WWII reconstruction and the fabric of Japanese society), so they invest themselves in the day to day (Sanchanta, 2004). The bottom line is that they are energetic, social, with large internet footprints, cash to spend, and for those like Yayoi, have an attitude that marketers love - that "money is no object." This is the perfect demographic 
landscape needed for a successful mobile-marketing campaign. Section 3 will look at the beneficial technological landscape for mobile marketing in Japan.

\section{Technological Omnipresence}

It's a simple truth that mobile marketing cannot exist without high-speed internet connections. Even the most well intentioned campaign would fail in the face of internet dead zones and slow download speeds. That being said, powerful internet connections are ubiquitous in Japan, making it a perfect canvas for mobile marketing. As far back as 2009, Japan had 99 million internet users, the third highest number of users in the world at that time (The World Fact Book: Japan, 2014). By 2012, 30\% of cities with the fastest broadband connections in the world were in Japan (Koeder, 2013). This is a staggering feat for a country with less than a dozen major urban centers, and mobile connectivity has surged in the wake of this computing power. Japan is now ranked second in the world for consumers with access to $4 \mathrm{G}$ mobile networks; only South Korea serves a higher percentage of its population (Husson, 2014). Overall, 80\% of all Japanese households are now connected to high-speed mobile broadband service (Husson, 2014). Smart/feature phone ownership has also grown to become ubiquitous. By $2012,80 \%$ of the population owned a mobile phone and $41 \%$ of those owners shopped through their phones (Koeder, 2013). The phones being used were already extremely high tech and are only becoming more so; 98\% had QR readers for scanning barcodes, 95\% had RFID, NCF or similar chips for touch connections to other devices, $95 \%$ had GPS connections, and $86 \%$ had digital tuners for playing and recording HQ quality videos (Koeder, 2013).

The end result of all of these statistics is that mobile marketers see a lot of money to be made. In 2012, \$1.74 billion USD was spent on mobile ads in Japan (Koeder, 2013), and internet shopping in Japan generated $\$ 52$ billion USD in revenue the same year (Mobile Cocooning, 2013). In 2014, advertisers are forecasted to spend $\$ 8.8$ billion USD on mobile ads in Japan (Marceux, 2014). How can marketers maximize this huge ad spend? Section 4 will look at the key characteristics that mobile campaigns must emulate to succeed in Japan.

\section{Give the People What They Want}

In 2013, McCann Erickson published a report entitled "The Truth About Connected You," which studied peoples' relationships to their mobile devices. Nine thousand people of all ages were interviewed worldwide, 1,000 of whom were in Japan, and five broad parameters emerged for effective mobile advertising. Campaigns should be Personal, Purposeful, Private, Playful, and include a "POW" factor that wows the audience (The Truth About Connected You, 2013). (More investigations can be found at http://truthcentral.mccann.com.) We can refer to these as the "5P's;" perhaps, these will some day surpass in importance the traditional "4P's" (Product, Place, Price, Promotion) discussed at the beginning of nearly every "Marketing 101" class.

The interviews with the Japanese participants largely matched the global findings, and the Tokyo editors of the study determined that, "Japanese told us they liked sophisticated and cute-looking images, but that was not enough to get them to participate, and so there needs to be a clear practical aspect as well as some kind of surprise to mobile advertising (The Truth 
About Connected You - Japan, 2013).” People expect mobile advertisers to know them well, and to offer information that's not just pertinent to their day, but that also impacts their lives. However, people can suffer from information overload; for a campaign to truly rise to the top, it must not only strike a tone of importance, but also be playful and exciting. And most importantly, a campaign must avoid crossing the line between "cute" and "irritating"/“creepy."

A similar survey of Japanese mobile users was conducted in 2011 by the Direct Marketing Educational Foundation (since June, 2013, known as Marketing EDGE - Educate, Develop, Grow, Employ), and published under the title "Determinants of Consumer Perceptions toward Mobile Advertising - A Comparison between Japan and Austria" It suffers from a lower-than-desirable sample size, only 170 Japanese business students. However, since it produced similar findings to those of "The Truth About Connected You," it should likely not be disregarded. What makes "Determinants..." particularly useful for a mobile marketer is that it calculated statistical relationships between an ad's characteristics and a viewer's perception of the ad's value.

The participants were shown an average of 16 SMS (text message) advertisements per week, and then asked five sets of questions about each advertisement. They were designed to reveal the participants' opinions on four key concepts:

1) Is the ad credible?

2) Is the ad irritating?

3) Does the ad offer "infotainment?"

4) Does the ad offer value to their day?

Each question was answered on a 1 to 5 Likert scale, 1 meaning "strongly agree" and 5 meaning "strongly disagree." The numerical responses were then compiled, and the responses to the first three sets of questions ("independent variables") were related to the responses to the fourth set (the "dependent variable.") These relationships allowed the study to statistically address questions such as, "If an ad is credible, does its perceived value increase?", "If an ad is irritating, does its perceived value decrease?", "Which of these factors most affect perceived value?", etc. Stated simply, this study wanted to know: When a participant responded " 1 " or " 5 " to whether an ad offered value to their day, can that be explained by their responses to the other questions about that ad?

The results of this study were interesting. Liu et al. (2012) computed the following path coefficients using a structural equation modeling approach:

Dependent variable: Perception of Advertising Value

Path coefficients: Infotainment $(+.112, \mathrm{p}<.01)$

$$
\begin{aligned}
& \text { Irritation }(-.085, .05<\mathrm{p}<.01) \\
& \text { Credibility }(+.116, \mathrm{p}<.01)
\end{aligned}
$$


Liu et al. (2012) also provided the results of a factor analysis to break down Infotainment, Irritation, Credibility, Advertising Value, and Attitudes Toward Advertising into its various components; see Appendix 1.

We can draw encouraging conclusions from the above numbers. First, common sense seems to prevail. The more credible an ad is perceived to be, the higher its perceived value to the consumer. Also, the more an ad offers "infotainment," also the higher its perceived value to the consumer. On the other hand, the more an ad is perceived as irritating, the lower its perceived value to the consumer. All three of these conclusions are statistically significant, with the two "added value" factors having $\mathrm{p}<.01$, while the irritation factor has $.01<\mathrm{p}<.05$. Second, the data indicate that the positive factors help more than the negative factor hurts; it may well be that if an ad is straddling the line between (cute) infotainment and irritation, it would still tend to net out as being perceived as offering positive value.

The study, "The Truth About Connected You," also offers caution against singling out a magical characteristic behind great campaigns. Their participants were asked, "Imagine you were shopping at a mall and you received a [personalized] coupon from the store you were browsing in at the time, would you... a) be more inclined to purchase something at that store, b) ignore the coupon and avoid the shop or brand, or c) complain to the mall about privacy concerns?" (The Truth About Connected You - Japan, 2013.) The survey showed a 50/50 split between Japanese consumers who would be more inclined to make a purchase and those who would avoid the brand and/or complain to security; detailed results are in Appendix 2. This level of distrust was higher than the global average, and higher still among Japanese men than women. The warning is clear; a mobile marketer in Japan may have a campaign which $50 \%$ of consumers believe is usefully personalized, while the other half thinks the campaign is creepy. Fifty percent may see a campaign as entertaining, while the other half sees it as irritating. What then should a marketer emulate? Section 5 will look at two case studies whose successes are reverberating on the Japanese mobile scene.

\section{Go Ahead, Make My Day}

McDonalds has established itself as a leader in mobile innovation since the platform came into existence. They opened their first mobile website in Japan in 2003, and then in 2008 launched kazasu mobile coupons which have turned into a data-mining dream. Users register on the McDonalds website, download the kazasu application with a unique membership ID, and begin to receive coupons on their phone. The gem is that phones with NFC chips can place and pay for orders by simply being tapped against a reader at the cash register. The order is instantly sent to the kitchen to be prepared as well as to a data center to be analyzed. Once an order pattern is established the coupons become more targeted, and the promotions become more tailored to the current customer experience. The data are analyzed for general indicators such as age, gender and location, but also for more finite points such as time of purchase and even the weather (Billich, 2010). At the same time, the mundane event of ordering a hamburger is transformed into a futuristic happening which customers love. One of many customers who shared their experiences on Youtube now has almost 300,000 views (http://www.youtube.com/watch?v=WoBuRJ3nQfI). 
Tailoring the coupons to be redeemed via NFC touch technology was no easy task. It required installing NFC readers in over 3,800 stores and opening a joint venture with NTT DoCoMo to manage the mobile payments and IT infrastructure (Gillen, 2010). However, it allows McDonalds to be one touch away from the nerve center of their customers' days. Furthermore, the feedback loop between the customer and the company becomes increasingly tight with each purchase, in a way that no other form of marketing can achieve (Gillen, 2010); mailed or emailed coupons may never be seen by the intended consumer, and a completely different consumer could redeem them; an entire extended family may share a membership card, or worse yet, forget to use their membership card.

The application caught on like wildfire. By 2010, just two years after being launched, the mobile site received 100 million page views per month and 4.5 million users downloaded the mobile application (Billich, 2010). The intelligence gathered was turned around so efficiently that by 2011 , McDonalds boasted that $85 \%$ of the mobile coupons were redeemed (Koeder, 2013). Based on interviews with professionals in Japan's mobile-marketing industry, this is the first campaign mentioned when speaking of models to emulate. The kazasu mobile coupons have brought McDonalds the success they hoped for and much more.

The Gap has also run a recently acclaimed mobile campaign based on NFC chips. Whereas McDonalds set out to reinvent traditional customer-company interactions, The Gap's campaign aimed to invent a whole new frontier in which customers express themselves. The campaign was called "High Five," and was presented as a competition during June, 2012 between The Gap's two trendiest stores in Tokyo, Ginza and Karajuku. In order to participate, customers downloaded an application to an NFC-enabled phone, linked it to their Facebook pages, and then synced the application to an NFC-enabled bracelet in one of the stores. If a participant liked an employee's outfit, he/she gave that employee a "high five" by touching his/her bracelet to the employee's phone. Instantly, an image of that outfit was posted to the customer's Facebook page, and the phone let out a cheer!

Although this campaign required a lot of setup, it inspired the public reaction The Gap was hoping for. More than 900 "high fives" took place, meaning almost 1,000 free ads for the company on their customers' Facebook pages. Beyond the actual participants, 6,000 people mentioned it per day on Facebook during the month-long competition, and 35 major media entities ran stories about it, including international outlets (Human Real "Like" Button, 2012). It did not create a spending splurge in the stores, but, by introducing such a radically new concept of advertising, this campaign did not necessarily need to be monetized to be a success. Will other companies follow the leads of these pioneers? Although they captivate our attention today, might campaigns like these seem ordinary in just a few years? Mobile innovation happens at light speed nowadays, and Section 6 will look into the future of mobile marketing.

\section{To Infinity and Beyond}

Those of us who remember the New Year's Eve of 1999 may still feel an attachment to the $20^{\text {th }}$ century. However, as the clock ticks on, research institutions are looking ahead to the year 2020 and further. Mobile marketing is presently a more or less one way' street: a company publicizes an event or product to consumers to entice them to buy. If the consumer buys, then 


\section{Macrothink}

the process simply repeats itself at a higher speed. In the future, however, there is a growing school of thought that marketing will be a two way street on which consumers market products, and companies reward them for their efforts. The consumers' online footprints will determine both their credibility (with other consumers) and their viability (with companies). McKinsey \& Company's analysts imagine this new paradigm playing out as follows - see Figure 1 (Dahlström, 2013):
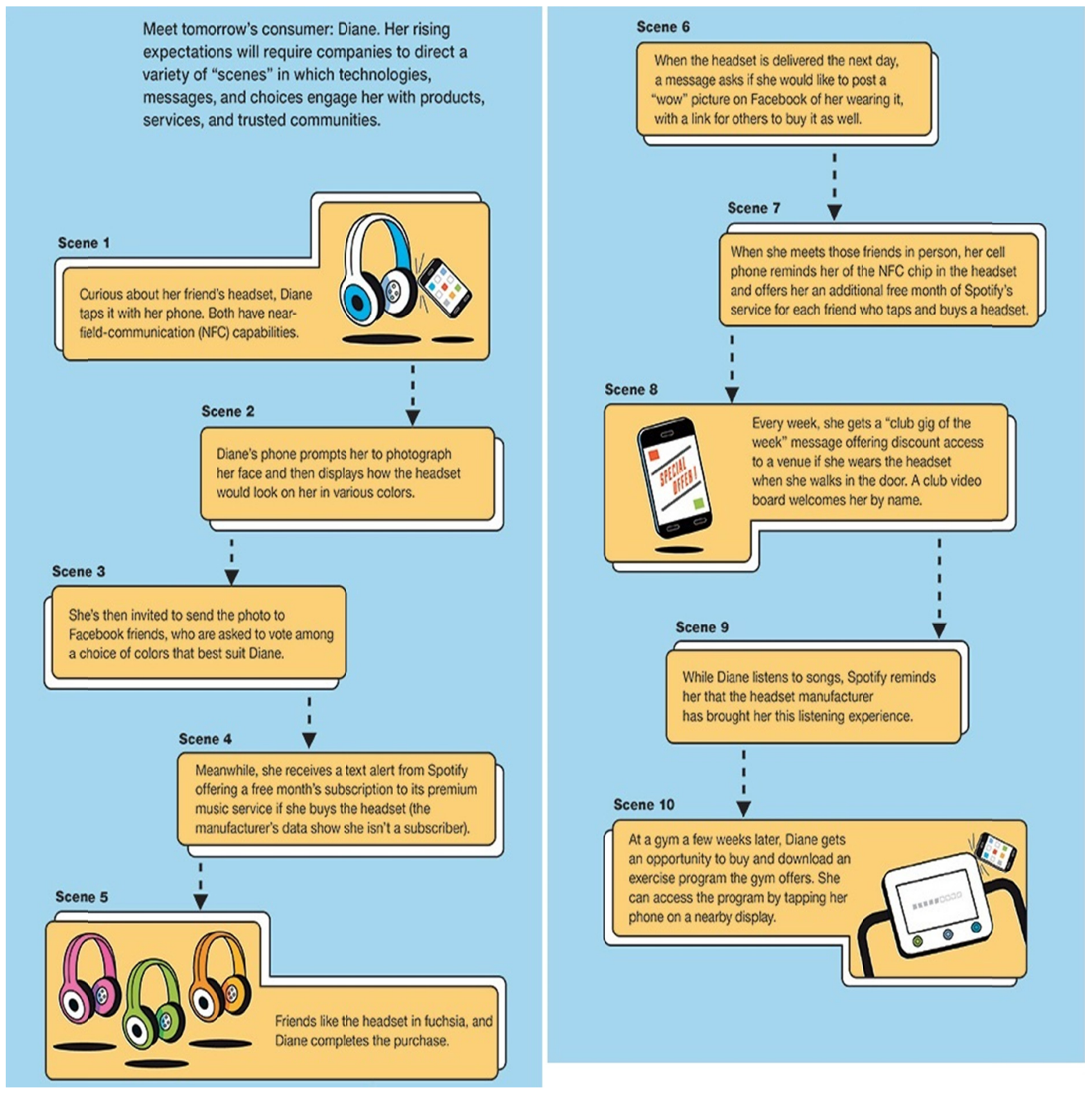

Figure 1. Anticipation of the playing out of the new paradigm

MRM Worldwide, a subsidiary of McCann Erickson, has produced a similar forecast of the future. Their findings, entitled " 4 Trends: Get Ready for the 2020s," have been presented at the Mobile World Congress in Barcelona, the Mobile Asia Expo in Shanghai, and other global platforms. Much like the chip-enabled headset in the McKinsey example, MRM 
foresees a shift away from "mobile phones" and towards a "mobility" of interconnected devices. They predict that 50 billion connected devices will be in use by 2020 (Koeder, 2014). These will be the infrastructure of the two-way marketing road between brands and consumers. In this new age, a brand's ratings on social informational websites like Yelp, Amazon and Facebook, as well as a consumer's connections and purchase history on those same sites, will count as a type of currency. Much like banks run credit checks, this currency can be used to run "social credit" checks for determining if a brand and/or consumer are trustworthy and worth investing in. The larger the social media footprint of either one, the more reason there will be for each to work together. This virtuous cycle can keep repeating itself for as long as both sides benefit.

What will Japan's mobile marketing look like in the year 2020? Will Japan be a global leader in these shifts or a follower? Will Japanese society be ready? All signs indicate that Japan will be a willing leader into the future, and moreover, that the future is already here. The neo-otaku culture of social research and consumption is already showing how consumers will place themselves at the center of brand outreach. Mobile connections are already fast and far reaching, allowing ever more captivating content to be shared with ever higher precision. By following the advice of mobile researchers, and emulating the successes of companies like McDonalds and The Gap, marketers can feel sure-footed even when walking down un-trodden paths. And since more than $\$ 8$ billion USD is being invested this year in mobile advertising for Japan, there is no question that the best concepts will rise to the top. Japan is currently a shining example of how high mobile campaigns can reach, and the future only looks brighter.

\section{What This Means for the Key Marketing Metric of Customer Lifetime Value}

There are, potentially, major marketing-strategy implications, based not only on the current state of mobile marketing in Japan (and the likelihood that the rest of the world follows the trend), but even more so if the future envisioned truly obtains.

One of the fastest growing areas of marketing strategy is the evaluation of customer value. It's only about 25 years ago that the idea of determining a company's Customer Lifetime Value (CLV), arguably, the most important marketing metric for determining optimal marketing strategy, "crossed over" from the area of direct/database marketing to become a part of traditional marketing education and implementation. Back then, direct/database marketing was just emerging, and was considered to be a very narrow area of marketing; nowadays, it, indeed, dominates marketing thinking. Two of the articles that engendered this crossover are (1) the article by Blattberg and Deighton (1996) in the Harvard Business Review, followed up by the article by Berger and Nasr (1998) in the Journal of Interactive Marketing (the latter journal, having recognized the paradigm shift taking place, changed its name from the Journal of Direct Marketing). In both of these articles, CLV was defined as the net present value of monetary profit and costs associated with a customer subsequent to his/her acquisition (i.e., ignoring acquisition cost). Since then, CLV analyses have recognized added aspects, beside solely the direct monetary measure; an example is to include "referral value" in a person's CLV - after all, if a person has a wide network of associates and is an 
opinion leader, his/her value as a customer may go way beyond his/her actual monetary purchases (e.g., Kumar et al., 2010).

One of the latest major additions to the CLV literature directly relates to the mobile marketing mushrooming in Japan that we have been describing. It is an article by Weinberg and Berger (2011), entitled, "Connected Customer Lifetime Value: The Impact of Social Media." They extended the general definition of Customer Lifetime Value (CLV) to include the value of influence associated with a consumer's network or connections. They introduce Connected Customer Lifetime Value (CCLV) as the present value of the net contribution associated with purchases made by a focal customer, plus the present value of the net contribution made by other customers due to the social-media influence of that focal customer. They highlight "social media engagement" as an important process associated with that influence, and propose Customer Social Media Value (CSMV) to represent the value derived through said social-media engagement. Individual social media are proposed to be differentially treated in their CSMV and CCLV mathematical models.

There is little doubt that the mobile marketing explosion in Japan connects (pun intended!) profoundly with the notion of Connected Customer Lifetime Value, and is likely to be the forerunner of giving additional prominence to CCLV as an advancement on earlier CLV models.

\section{Conclusions}

There is no doubt that large changes are taking place in the world of Mobile Marketing. Indeed, an argument can be made that a revolution is taking place, as opposed to a simple evolution! There is also no doubt that Japan is among the leaders of this revolution.

What is "normal" in the area of mobile marketing has changed. Aspects of mobile marketing, such as re-tweeted posts and Facebook entries, and others, are increasing becoming assets, as features of mobile marketing, such as demonstrated product knowledge, are becoming the criteria on which various groups are evaluating peers. It won't be long before this evaluation process spreads to the evaluation of applicants for selected employment positions.

More and more money is being spent, by consumers, by companies, and indeed, by government agencies, on what can be thought of as "technological omnipresence." As time passes, more and more studies are being done to determine and refine the optimal way to implement corresponding marketing strategies to take advantage of this mobile marketing

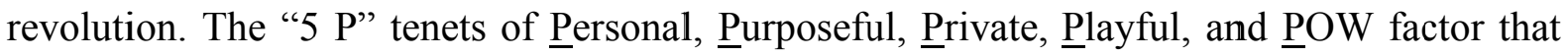
are driving Japanese revenue may soon be the basis of all campaigns.

This paradigm change in the world of mobile marketing has major implications for marketing metrics and specifically, the core marketing metric of customer lifetime value (CLV). It surely will not be long before mobile marketing considerations lead to rich additions to the frequently-cited CLV, and correspondingly, the marketing-strategy, literature. 


\section{Appendix 1}

\begin{tabular}{|c|c|c|c|}
\hline \multicolumn{4}{|l|}{$\begin{array}{l}\text { Table } 3 \\
\text { Reliability and factor loadings of scale items. }\end{array}$} \\
\hline \multirow[t]{2}{*}{ Items } & \multicolumn{3}{|c|}{ Japanese sample $(n=170)$} \\
\hline & $\begin{array}{l}\text { Factor } \\
\text { loadings }\end{array}$ & $\begin{array}{l}\text { Composite } \\
\text { reliability }\end{array}$ & AVE \\
\hline Infotainment & & 0.87 & 0.58 \\
\hline SMS advertising is entertaining & 0.75 & & \\
\hline SMS advertising is enjoyable & 0.79 & & \\
\hline SMS adverting is pleasing & 0.67 & & \\
\hline SMS advertising is a good source of information & 0.76 & & \\
\hline SMS advertising is a good source of up to date product information & 0.82 & & \\
\hline Imitation & & 0.72 & 0.57 \\
\hline SMS advertising is annoying & 0.63 & & \\
\hline SMS advertising is irritating & 0.86 & & \\
\hline Credibility & & 0.80 & 0.57 \\
\hline SMS advertising is convincing & 0.76 & & \\
\hline SMS advertising is believable & 0.75 & & \\
\hline SMS advertising is credible. & 0.75 & & \\
\hline Advertising value & & 0.79 & 0.56 \\
\hline SMS advertising is useful & 0.86 & & \\
\hline SMS advertising is valuable & 0.59 & & \\
\hline SMS advertising is important & 0.76 & & \\
\hline Attitudes toward advertising & & 0.83 & 0.63 \\
\hline SMS advertising helps raise our standard of living & 0.81 & & \\
\hline SMS helps me to find products that match my personality and interests & 0.82 & & \\
\hline SMS Advertising helps me buy the best brand for a given price & 0.74 & & \\
\hline \multicolumn{4}{|l|}{ CFA model goodness of fit indexes: } \\
\hline Chi-square on $203 \mathrm{df}$ & 370.971 & & \\
\hline $\mathrm{CFI}$ & 0.943 & & \\
\hline IFI & 0.944 & & \\
\hline RMSEA & 0.050 & & \\
\hline
\end{tabular}




\section{Macrothink}

\section{Appendix 2}

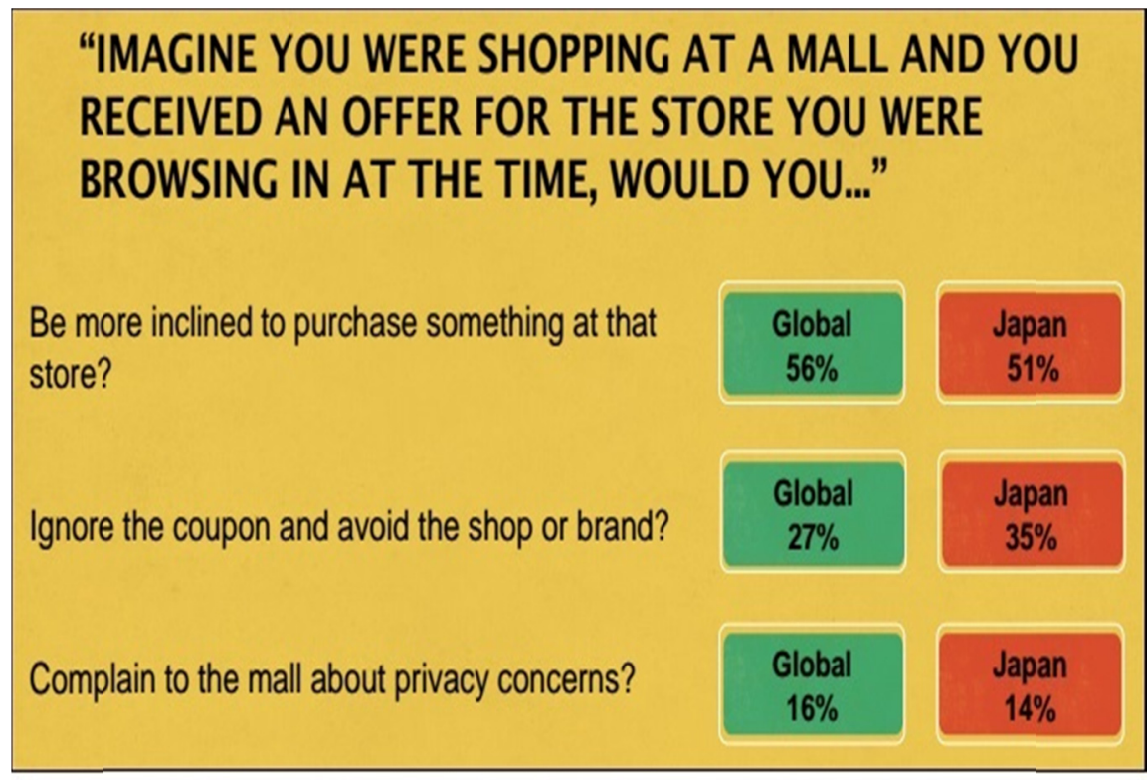

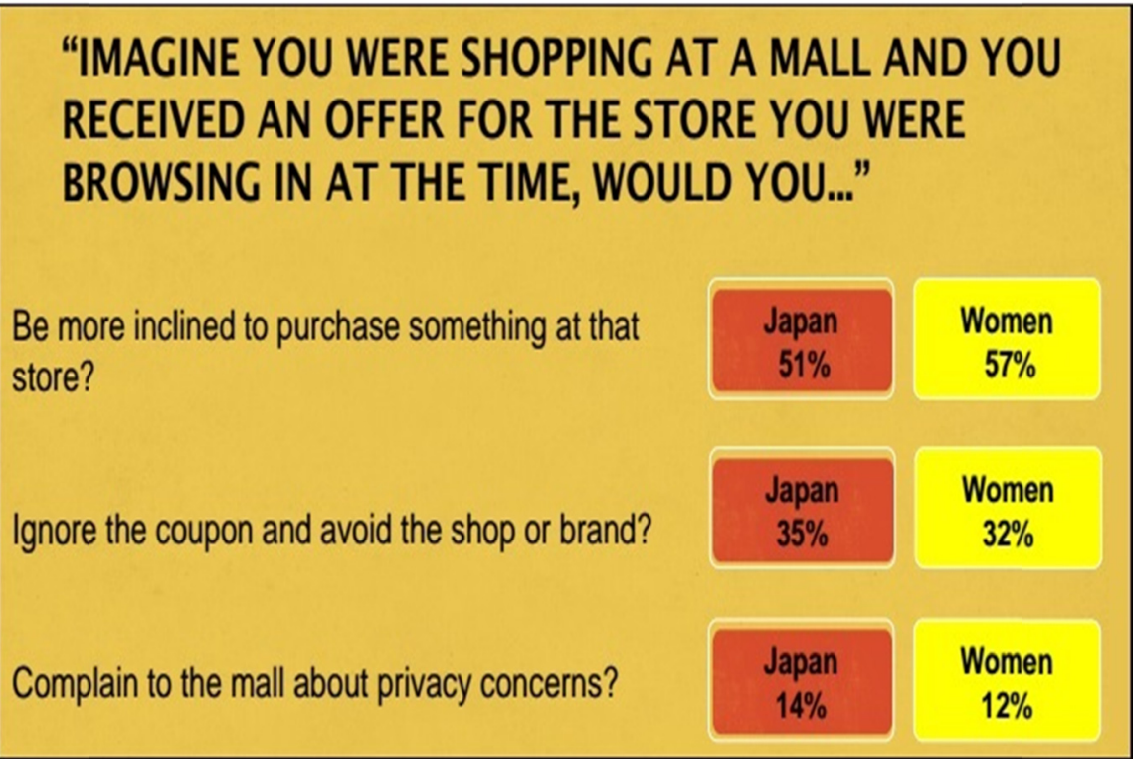

\section{References}

Berger, P., \& Nasr, N. (1998). Customer Lifetime Value: Marketing Models and Applications. Journal of Interactive Marketing, $\quad 12(1), \quad$ 17-30. http://dx.doi.org/10.1002/(SICI)1520-6653(199824)12:1\%3C17::AID-DIR3\%3E3.0.CO;2-K

Billich, C. (2010). The Insider's Guide to Mobile Web Marketing in Japan. Retrieved June 27, 2014, from http://mobithinking.com/guide-mobile-Web-Japan

Blattberg, R., \& Deighton, J. (1996). Managing Marketing by the Customer Equity Test. Harvard Business Review, 74, 136-144. http://dx.doi.org/10.1142/9789814287067_0013 


\section{Macrothink}

International Journal of Social Science Research

ISSN 2327-5510

2014, Vol. 2, No. 2

Dahlström, P., \& Edelman, D. (2013). The Coming Era of 'on-demand' Marketing. McKinsey Quarterly. McKinsey \& Company.

Fournier, S., \& Richins, M. (1991). Some Theoretical and Popular Notions Concerning Materialism. Journal of Social Behavior and Personality, 6(6). 403-414.

Gillen, R. (2010). A Merchant's Argument For Mobile Contactless Technology. Celent Banking Blog. Celent. Web. http://bankingblog.celent.com/2010/07/05/a-merchants-argument-for-mobile-contactless-tech nology/

Human "Like" Button. (2012). Spikes Asia. Web. http://www.spikes.asia/winners/2012/promo/entry.cfm?entryid=348\&award=101\&order=0\& direction $=1$

Husson, T. (2014). Mobile In Japan: What Marketers Need To Know. Forrester Research Inc.

Kasser, T. Ryan, R. Couchman, C. Sheldon, K. (2004) Materialistic values: Their causes and consequences, in Psychology and Consumer Culture, T. Kasser, \& A. D. Kanner (eds.). American Psychological Association: Washington, D.C. http://dx.doi.org/10.1037/10658-002

Koeder, M. (2013) The Power of Mobile Advertising: A Look at Japan. MRM McCann. Medientage. Munich, Germany. October. Conference Presentation.

Koeder, M. (2014). 4 Trends: Get Ready for the 2020s. MRM McCann. Mobile World Congress. Barcelona, Spain. February. Conference Presentation.

Kumar, V. Petersen, J. Leone, R. (2010). Driving Profitability by Encouraging Customer Referrals. Journal of Marketing, 74(5), 1-17. http://dx.doi.org/10.1509/jmkg.74.5.1

Liu, C. Sinkovics, R. Pezderka, N. Haghiriam, P. (2012). Determinants of Consumer Perceptions toward Mobile Advertising - A Comparison between Japan and Austria. Journal of Interactive Marketing, 26(1), 21-32. http://dx.doi.org/10.1016/j.intmar.2011.07.002

Marceux, P. (2014). Top 3 Online Adspen Markets in 2014: USA, Japan, and the UK. Euromonitor International. May 7.

McCaughan, D. (2010). Why Japanese Youth Want to Be 'Otaku' and What it Means. Advertising Age. June 14.

Mobile Cocooning: How Growing Reliance on Smart Devices is Influencing Consumer Behaviour. (2013). Euromonitor International. September 25.

Sanchanta, M. (2004). The Targeting of Japan's Young Tribes. Financial Times. October 14.

The Truth About Connected You. (2013). McCann Truth Central. McCann Worldgroup.

The Truth About Connected You - Japan. (2013). McCann Truth Central. McCann Worldgroup. 


\section{Macrothink}

International Journal of Social Science Research

ISSN 2327-5510 2014, Vol. 2, No. 2

The Truth About Social. (2011). McCann Truth Central. McCann Worldgroup.

The World Fact Book: Japan. (2014). Central Intelligence Agency (US). June 20.

Veblen, T. (1899). The Theory of the Leisure Class: An Economic Study of Institutions. New York: MacMillian Press.

Weinberg, B., \& Berger. P. (2011). Connected Customer Lifetime Value: The Impact of Social Media. Journal of Direct, Data, and Digital Marketing Practice, 12(4). 328-344. http://dx.doi.org/10.1057/dddmp.2011.2

\section{Copyright Disclaimer}

Copyright for this article is retained by the author(s), with first publication rights granted to the journal.

This is an open-access article distributed under the terms and conditions of the Creative Commons Attribution license (http://creativecommons.org/licenses/by/3.0/). 